\title{
Enhanced Air-Sea Exchange of Heat and Carbon Dioxide Over a High Arctic Fjord During Unstable Very-Close-to-Neutral Conditions
}

\author{
A. Andersson ${ }^{1,2}$ (D) A. Sjöblom ${ }^{1,3} \cdot$ E. Sahlée $^{1} \cdot$ E. Falck $^{3} \cdot$ A. Rutgersson $^{1}$ \\ Received: 12 December 2017 / Accepted: 13 November 2018 / Published online: 29 November 2018 \\ (c) The Author(s) 2018
}

\begin{abstract}
Eddy-covariance measurements made in the marine atmospheric boundary layer above a high Arctic fjord (Adventfjorden, Svalbard) are analyzed. When conditions are unstable, but close to neutral $-0.1<z / L<0$, where $z$ is the height, and $L$ is the Obukhov length, the exchange coefficient for sensible heat $C_{H}$ is significantly enhanced compared with that expected from classical surface-layer theory. Cospectra of the vertical velocity component $(w)$ and temperature $(T)$ reveal that a high-frequency peak develops at $f \approx 1 \mathrm{~Hz}$ for $z / L>-0.15$. A quadrant analysis reveals that the contribution from downdrafts to the vertical heat flux increases as conditions become close to neutral. These findings are the signature of the evolving unstable very-close-to-neutral (UVCN) regime previously shown to enhance the magnitude of sensible and latent heat fluxes in the marine surface layer over the Baltic Sea. Our data reveal the significance of the UVCN regime for the vertical flux of the carbon dioxide $\left(\mathrm{CO}_{2}\right)$ concentration $(C)$. The cospectrum of $w$ and $C$ clearly shows how the high-frequency peak grows in magnitude for $z / L>-0.15$, while the high-frequency peak dominates for $z / L>-0.02$. As found for the heat flux, the quadrant analysis of the $\mathrm{CO}_{2}$ flux shows a connection between the additional small-scale turbulence and downdrafts from above. In contrast to the vertical fluxes of sensible and latent heat, which are primarily enhanced by the very different properties of the air from aloft (colder and drier) during UVCN conditions, the increase in the air-sea transfer of $\mathrm{CO}_{2}$ is possibly a result of the additional small-scale turbulence causing an increase in the water-side turbulence. The data indicate an increase in the gas-transfer velocity for $\mathrm{CO}_{2}$ for $z / L>-0.15$ but with a large scatter. During the nearly 2 months of continuous measurements (March-April 2013), as much as $36 \%$ of all data are associated with the stability range $-0.15<z / L<0$, suggesting that the UVCN regime is of significance in the wintertime Arctic for the air-sea transfer of heat and possibly also $\mathrm{CO}_{2}$.
\end{abstract}

Keywords Air-sea exchange $\cdot$ Arctic $\cdot \mathrm{CO}_{2} \cdot$ Gas-transfer velocity $\cdot$ Unstable very-close-to-neutral

\footnotetext{
A. Andersson

andreas.andersson@miun.se
}

Extended author information available on the last page of the article 


\section{Introduction}

Oceans have taken up approximately $25 \%$ of the anthropogenically emitted carbon dioxide $\left(\mathrm{CO}_{2}\right)$ into the atmosphere, causing ocean acidification (Le Quéré et al. 2015), while limiting the climate impact. For accurate estimates of the global carbon budget, the net uptake of $\mathrm{CO}_{2}$ and its variation with time is crucial to quantify. High-latitude seas and marine polar waters are regions of climatic importance since they constitute a major net sink of atmospheric $\mathrm{CO}_{2}$. In order to understand the ocean response to the increasing emissions of $\mathrm{CO}_{2}$ into the atmosphere, a correct description of the air-sea gas transfer at these latitudes is crucial. Studies of air-sea gas exchange in the high Arctic environment are, however, few and a detailed description of the processes controlling the transfer efficiency in these areas is lacking. The gas flux of a non-reactive gas such as $\mathrm{CO}_{2}$ can be computed using the bulk flux equation,

$$
F_{c}=k_{c} K_{0}\left(p_{c w}-p_{c a}\right),
$$

where $k_{c}$ is the gas-transfer velocity for $\mathrm{CO}_{2}, K_{0}$ is a gas-specific solubility constant, $p_{c w}$ is the partial pressure of $\mathrm{CO}_{2}$ in the surface seawater, and $p_{c a}$ is the partial pressure of $\mathrm{CO}_{2}$ in the atmosphere. Despite the simplicity of Eq. 1, the physical complexity in describing air-sea gas transfer is contained within the parametrization of the gas-transfer velocity, which essentially describes the efficiency of the transfer across the air-sea interface, and is controlled by several processes, such as molecular diffusion, bubble mediated transfer, and surface renewal. In the presence of turbulence, the molecular diffusion layer separating air and water deforms, which in turn enhances the air-sea gas-transfer velocity, thus an increase in turbulence results in higher values of $k_{c}$ and, thus, a larger air-sea $\mathrm{CO}_{2}$ flux. For a gas of low solubility, such as $\mathrm{CO}_{2}$, the interfacial gas transfer is almost exclusively driven by the magnitude of turbulence in the surface water. Water-side turbulence is in turn caused by a variety of processes, such as wind stress on the water surface (Liss and Merlivat 1986; Wanninkhof 1992; Wanninkhof et al. 2009), breaking waves and bubbles (Woolf 1993, 1997; Asher and Wanninkhof 1998; Bell et al. 2017), water-side convection (MacIntyre et al. 2002; Rutgersson and Smedman 2010; Rutgersson et al. 2011; Andersson et al. 2017), and rain (Ho et al. 1997, 2004; Zappa et al. 2009; Drushka et al. 2016).

We investigate the turbulent characteristics of the vertical fluxes of both heat and $\mathrm{CO}_{2}$ during unstable, but near-neutral conditions. Former studies over land and the open sea during unstable very-close-to-neutral (UVCN) conditions in combination with relatively high wind speeds have shown an enhancement of the vertical fluxes of temperature $(T)$ and humidity (Smedman et al. 2007a, b; Sahlée et al. 2008a, b). The larger fluxes are associated with downdrafts of cold and dry air by detached eddies originating from the mixed layer, manifest as additional small-scale turbulence in the cospectra of $w$ and $T$. Our focus is on the possible importance of the UVCN regime for the air-sea transfer of heat and $\mathrm{CO}_{2}$ in the wintertime marine Arctic using eddy-covariance data taken at Adventfjorden, Svalbard (Fig. 1). We present data indicating a possible impact of the additional turbulence (found for unstable, but near-neutral conditions) related to the UVCN regime on the air-sea gas-transfer velocity for $\mathrm{CO}_{2}$. 

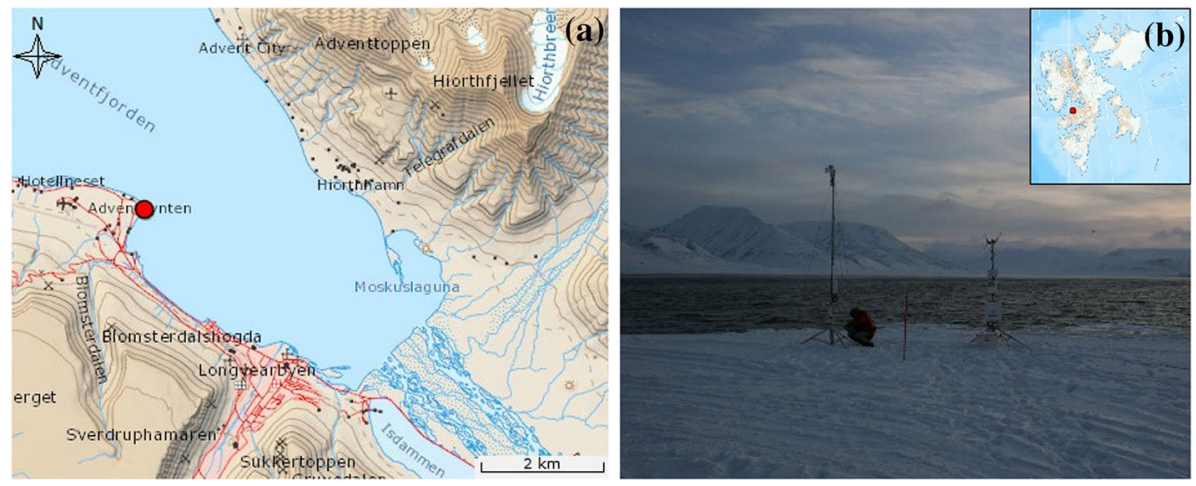

Fig. 1 a Location of the Adventfjorden site $\left(78.246^{\circ} \mathrm{N}, 15.554^{\circ} \mathrm{E}\right)$ (red dot). b Photo of the Adventfjorden site showing the eddy-covariance tower (right) and profile tower (left), and the Adventfjord in the background. The inset is a map of Toposvalbard (Norwegian Polar Institute 2016)

\section{Theory}

\subsection{Formation of the Convective Boundary Layer}

When cold air from snow-covered land or from polar ice is advected over the open water of a fjord, the atmospheric boundary layer is rapidly transformed into a convective boundary layer (CBL). The large air-water temperature difference is typically in the range of $10-25^{\circ} \mathrm{C}$ and, in combination with moderate to high wind speeds, results in large turbulent fluxes of sensible and latent heat throughout the boundary layer. The development of the CBL over a fjord is similar to the development of the convective internal boundary layer found over leads and polynyas (e.g. Andreas and Murphy 1986; Andreas and Cash 1999; Else et al. 2011; Tetzlaff et al. 2015) caused by the step change of surface heat and humidity fluxes. The height $h_{b}$ of the CBL increases with the distance $x$ from the upwind land/ice edge, for which Garratt (1992) provides the expression

$$
\left(h_{b} / z_{02}\right)\left(\ln \left(h_{b} / z_{02}\right)-1\right)+1=A x / z_{02}
$$

to calculate the growth of $h_{b}$ with $x$. Here, $z_{02}$ is the roughness length of the smooth surface, and the dimensionless constant $A \approx 1$. Within the CBL, the generally accepted model is that the wind stress acting on the surface, and due to the mean wind speed and/or surface convection, generates small eddies formed at the surface, which increase in size with height.

\subsection{Gas-Transfer Velocity}

When the flux $F_{c}$ and the difference in partial pressure of $\mathrm{CO}_{2}\left(\Delta p_{c}\right)$ between the surface water and at the measurement height are known, the transfer velocity $k_{c}$ follows from Eq. 1 as

$$
k_{c}=F_{c}\left(K_{0} \Delta p_{c}\right)^{-1}
$$

To compare measurements of gas-transfer velocities for different gases and across a wide range of sea-surface temperatures, the measured values of $k_{c}$ are corrected for changes in 
molecular diffusivity and viscosity and scaled to the corresponding counterpart for $\mathrm{CO}_{2}$ at $20{ }^{\circ} \mathrm{C}$ in seawater $\left(k_{660}\right)$ through the Schmidt number $S c=660$,

$$
k_{660}=k_{c}(S c / 660)^{-1} .
$$

Equations 3 and 4 are valid for situations where the air-sea gas exchange is governed by interfacial gas exchange, and the in situ temperature-dependent value of $S c$ is obtained using the parametrization of Wanninkhof (1992). In a review article by Wanninkhof et al. (2009), a parametrization of the gas-transfer velocity was presented relating the value of $k_{C}$ to the wind speed at $10-\mathrm{m}$ height above sea level $U_{10}$. This is the state-of-the-art parametrization, since it is based on both theoretical concepts and measurements, and includes the effects from both low and high wind-speed regimes through

$$
k_{W 09}=3+0.1 U_{10}+0.064 U_{10}^{2}+0.0011 U_{10}^{3} .
$$

In Andersson et al. (2017), the effect of the water-side convection on the value of $k_{660}$ was investigated using eddy-covariance measurements from a Svalbard fjord (Adventfjorden). After scaling the measured values of $k_{660}$ to represent open-sea conditions, and removing the impact of the wind speed on $k_{660}$ according to Eq. 5, Andersson et al. (2017) found a relation between the gas-transfer velocity for $\mathrm{CO}_{2}\left(k_{w s c}=k_{660}-k_{W 09}\right)$ and the water-side convection $w * w$ as

$$
k_{w s c}=2300 w_{*_{w}}-17,
$$

where $w * w$ is determined using the expression from Jeffery et al. (2007),

$$
w_{* w}=\left(B z_{m l}\right)^{1 / 3} .
$$

Here, $B$ is the buoyancy flux at the sea surface, and $z_{m l}$ denotes the mixed-layer depth in water. We follow the scaling concept presented in Andersson et al. (2017), and use Eqs. 6 and 7 to calculate the contribution from water-side convection to the value of $k_{660}$.

\subsection{Transfer Coefficient}

From measurements of the turbulent flux of potential temperature $\left(\overline{w^{\prime} \theta^{\prime}}\right)$, the transfer coefficient for sensible heat $\left(C_{H}\right)$ can be obtained through the bulk relation

$$
C_{H}=\frac{\overline{w^{\prime} \theta^{\prime}}}{\left(U_{10}-U_{w}\right)\left(\theta_{w}-\theta_{10}\right)},
$$

where $U_{w}$ is the wind speed at the sea surface, $\theta_{10}$ is the potential temperature $(\mathrm{K})$ at 10 $\mathrm{m}$ height, and $\theta_{w}$ is the temperature at $z=z_{T}$, where $z_{T}$ is the scalar roughness length for temperature, and $\theta_{w}$ is approximated by the sea-surface temperature. Here, the value of $C_{H}$ is determined from measurements of the potential temperature $\theta_{4}$ and wind speed $U_{4}$ taken at 4-m height. Within the surface layer, the turbulent fluxes are assumed to be approximately constant, and, provided Monin-Obukhov similarity theory (MOST) is valid, the non-dimensional profiles of $U$ and $\theta$ over a horizontally-homogenous surface can be expressed as

$$
\frac{\partial U}{\partial z} \frac{\kappa z}{u_{*}}=\phi_{m}(z / L)
$$

and 


$$
\frac{\partial \theta}{\partial z} \frac{\kappa z}{T_{*}}=\phi_{H}(z / L)
$$

respectively, where $T_{*}=-\overline{\left(w^{\prime} \theta^{\prime}\right)_{0}} / u_{*}$ is the temperature scale, and the Obukhov length is

$$
L=-\frac{u_{*}^{3} T_{0}}{\kappa g\left(\overline{w^{\prime} \theta^{\prime}}\right)},
$$

where $g$ is the acceleration due to gravity, and $T_{0}$ is the mean temperature of the surface layer. After vertical integration of Eq. 9, the surface-layer profile $U(z)$ is

$$
U-U_{w}=\frac{u_{*}}{k}\left[\ln \left(z / z_{0}\right)-\psi_{m}\right],
$$

and where $z_{0}$ is the roughness length, and $U_{w}$ is the wind speed at the sea surface (here, $U_{w}$ is set to zero), with the small term $\psi\left(z_{0} / L\right)$ neglected. During unstable conditions, we base the function $\phi_{m}$ on (Högström 1996)

$$
\phi_{m}=(1-19 z / L)^{-1 / 4} \text {. }
$$

\subsection{Spectral Analysis}

The energy spectrum relates the size of the turbulent eddies in terms of the frequency $(n)$ to the energy of, for example, the specified quantities $U$ or $C$. Following Kolmogorov theory, and by applying the Taylor hypothesis, the energy spectrum $S(n)$ in the inertial subrange for the longitudinal velocity component can be expressed as

$$
n S_{u}(n)=\frac{\alpha_{k}}{2 \pi^{2 / 3}} \varepsilon^{2 / 3} n^{-2 / 3} U^{2 / 3},
$$

where $\varepsilon$ is the dissipation rate of turbulent kinetic energy, and $\alpha_{k}$ is the Kolmogorov constant. For the wind speed $U, \alpha_{k}=0.52$, although studies have shown a dependence on the wave age (Sjöblom and Smedman 2004), $\alpha_{k} \approx 0.8$ for temperature, but $0.68 \leq \alpha_{k} \leq 0.89$ for $\mathrm{CO}_{2}$ (see, e.g., Othaki 1982; Verma and Anderson 1984; Norman et al. 2012). Within the inertial subrange, the value of $n S_{u}(n)$ should follow a $-2 / 3$ slope when plotted against the logarithm of frequency $n$. As shown in several studies, Kolmogorov theory also applies for the quantities $v$ (transverse velocity component), $w, T$ (Kaimal et al. 1972), $q$ (specific humidity) and $C$ (Ohtaki and Matsui 1982; Anderson and Verma 1985; Sahlée et al. 2008c), and probably also for the oxygen concentration (Andersson et al. 2014). For the investigation of the turbulent flux, the cospectrum $\left(C_{w x}\right)$ is preferably studied, where the eddy size is shown as a function of the frequency, and the scalar flux $F_{x}$ is computed as the integral of the cospectrum $\left(C_{w x}\right)$,

$$
F_{x}=\int_{-\infty}^{\infty} C_{w x}(n) d n=\overline{w^{\prime} x^{\prime}} .
$$

\subsection{The Unstable Very-Close-to-Neutral Regime}

During moderate instability, the boundary layer is characterized by organized longitudinal eddies of roll-type structure (e.g. Mason and Sykes 1982), giving a normalized spectral peak located at $f \approx 10^{-2} \mathrm{~Hz}$, and the MOST approach is valid. As the boundary layer becomes closer to neutral $(-L>150 \mathrm{~m})$ due to an increase in wind speed or a decrease in the air-sea temperature difference $(\Delta T)$, the small-scale turbulence dominates the spectrum of 
temperature (see Smedman et al. 2007a, b). This new regime is denoted as the unstable veryclose-to-neutral (UVCN) regime, and is characterized by a development of a secondary peak at higher frequencies in the spectrum of $T$ and in the cospectrum of $w T$. Simultaneously, the value of $C_{H}$ increases with increasing wind speed, and MOST becomes no longer valid. From a quadrant analysis of the value of $w T$, the additional small-scale turbulence coincides with an increase in the contribution to the heat flux from downdrafts of cold air from layers aloft. In the transition between the more unstable branch characterized by large-eddy structures and the UVCN regime, an intermediate range is found at the intersection of these two regimes characterized by "camel-shaped" spectra and cospectra with two distinct maxima: a largescale maximum in the energy-containing range related to local production, and a maximum at higher frequency related to the UVCN regime. Smedman et al. (2007a) argued that this small-scale turbulence is explained by detached eddies created by shear in the upper part of the boundary layer. The concept of detached eddies for high Reynolds numbers, which was explained in Hunt and Morrison (2000) and Hunt and Carlotti (2001), and later confirmed by measurements (Högström et al. 2002), says that, as detached eddies move downwards, they are deformed due to blocking and stretching by the surface-layer wind shear. While the UVCN regime is found to occur for approximately $-L>150 \mathrm{~m}$, Smedman et al. (2007a) speculated that the value of $h / L$, with $h$ the boundary-layer height, would be the controlling parameter, but did not possess any measurements of $h$. In Sahlée et al. (2008a), the additional turbulence typical of the transition regime was found to significantly increase the vertical turbulent flux of humidity.

\section{Site and Measurements}

\subsection{The Adventpynten Site}

During the period from 7 March to 22 April 2013, a field campaign was conducted in the area of Adventfjorden close to Longyearbyen, Svalbard in Norway (Fig. 1). Adventfjorden is a typical, high Arctic fjord where the valley opens out into the water, giving a fjord surrounded by steep mountains. However, the terrain at the Adventpynten site (see Fig. 1a) is relatively flat, resulting in a smooth transition from land to water. As a side fjord to the larger Isfjorden, Adventfjorden is about $7 \mathrm{~km}$ long, and the distance across the fjord from Adventpynten to the other side of the fjord is about $3.5 \mathrm{~km}$. The site contains (Fig. 1b) one tower equipped with an eddy-covariance system installed at 3-m height above mean sea level, and a second tower equipped with slow-response instruments measuring the wind speed, temperature, and humidity at two heights ( $0.5 \mathrm{~m}$ and $4 \mathrm{~m}$ above ground). The eddy-covariance system consists of one CSAT3 sonic anemometer (Campbell Scientific, North Logan, Utah, USA) measuring the three velocity components and temperature, and a LICOR-7500A gas analyzer (LI-COR Inc., Lincoln, Nebraska, USA) measuring the humidity, $\mathrm{CO}_{2}$ concentration, and pressure. On five occasions during the period 14-25 March, measurements from a boat were taken within the flux footprint. A net radiometer (CNR-1, Kipp \& Zonen, Delft, The Netherlands) installed on a boom at the front of the boat measured the net radiation over water. Measurements of the sea-surface temperature, partial pressure of $\mathrm{CO}_{2}$, and the water salinity were also recorded, and vertical profiles of water temperature were taken every 15 min using a conductivity, temperature, and depth sensor (CTD, SeaBird SBE 19plus V2 SeaCat, Seabird Electronics Inc., Bellevue, Washington, USA). 


\subsection{Data Analysis}

Based on a footprint analysis and spectral/cospectral evaluations (Andersson et al. 2017), data not associated with a wind direction in the range of $080^{\circ}-150^{\circ}$ were discarded to minimize the influence of land. A double rotation was performed on the eddy-covariance velocity data, with vectors first rotated into the mean wind direction and then tilt corrected to yield a zero mean vertical velocity component, giving a velocity vector aligned with the mean wind direction. The gas-analyzer data were screened with a filter using the mean concentrations of humidity and $\mathrm{CO}_{2}$ to exclude data with icing on the device. Data were then despiked and divided into 30-min blocks, with data not fulfilling the skewness and flatness criteria of Vickers and Mahrt (1997) discarded. Every individual block of data was linearly detrended and corrected for time lags caused by the separation distance between the sonic anemometer and the gas analyzer. Corrections for density fluctuations due to heat and moisture fluxes were made based on Webb et al. (1980). For the spectral and cospectral analysis of $\mathrm{CO}_{2}$, the density correction was performed directly on the raw signal following the method presented in Sahlée et al. (2008c), where the output signal was transformed into a mixing ratio to avoid the influence from temperature and humidity variations on the shape of the $w C$ cospectrum. Here, cospectra consist of 21 points, with each point representing a normalized mean cospectral estimate for the respective frequency. The data and site are described in detail in Andersson et al. (2017).

\section{Results}

\subsection{Heat Transfer}

Relatively high wind speeds (up to $12 \mathrm{~m} \mathrm{~s}^{-1}$ ) and air temperatures consistently below zero characterized the weather conditions during the field campaign (Fig. 2a, b). The prevailing wind direction was from the south-east, corresponding to flow from the Advent valley out over the fjord. Flow from the northern sector (into the fjord) was rarely observed. At the beginning of the field campaign, a period with ice formation in the Adventfjord (black bars, Fig. 2d) occurred, and by 9 March a major part of the fjord upstream from the tower was covered with ice but with patches of open water. The heat fluxes drastically decreased and the atmospheric stability (Fig. 2c) altered between unstable and stable conditions, typically with $-2<z / L<0.1$. On 11 March, a cold-air outbreak occurred with wind speeds at 3 -m height as high as $12 \mathrm{~m} \mathrm{~s}^{-1}$ in combination with air temperatures $<-18^{\circ} \mathrm{C}$. The ice quickly disappeared, the sensible heat flux increased up to $400 \mathrm{~W} \mathrm{~m}^{-2}$, and latent heat fluxes were $>150 \mathrm{~W} \mathrm{~m}^{-2}$ (not shown). Several periods with high wind speeds, large heat fluxes, and unstable, but near-neutral, conditions could be distinguished. The atmospheric stability (Fig. 2c) generally varied from unstable during more calm conditions to unstable, but near-neutral, conditions in the range $-0.2<z / L<-0.03$ during higher wind-speed conditions ( $34 \%$ of the time). The large air-sea gradient in temperature also set an upper limit for the stability, and only $5 \%$ of the data were found in the stability range $-0.03<z / L<0$. The combination of cold, humid air and relatively high wind speeds during the first half of the field campaign caused severe icing on the instruments. The gas analyzer and hence the $\mathrm{CO}_{2}$ signal was found to be sensitive to icing, causing large false positive fluxes of $\mathrm{CO}_{2}$, which can be observed frequently during the first three weeks of the campaign (Fig. 2e). Useful data during this period were reduced to some hours just after the daily maintenance of the instruments. After the first three weeks, the flux $F_{c}$ (Fig. 2e) was directed downwards as expected given the 

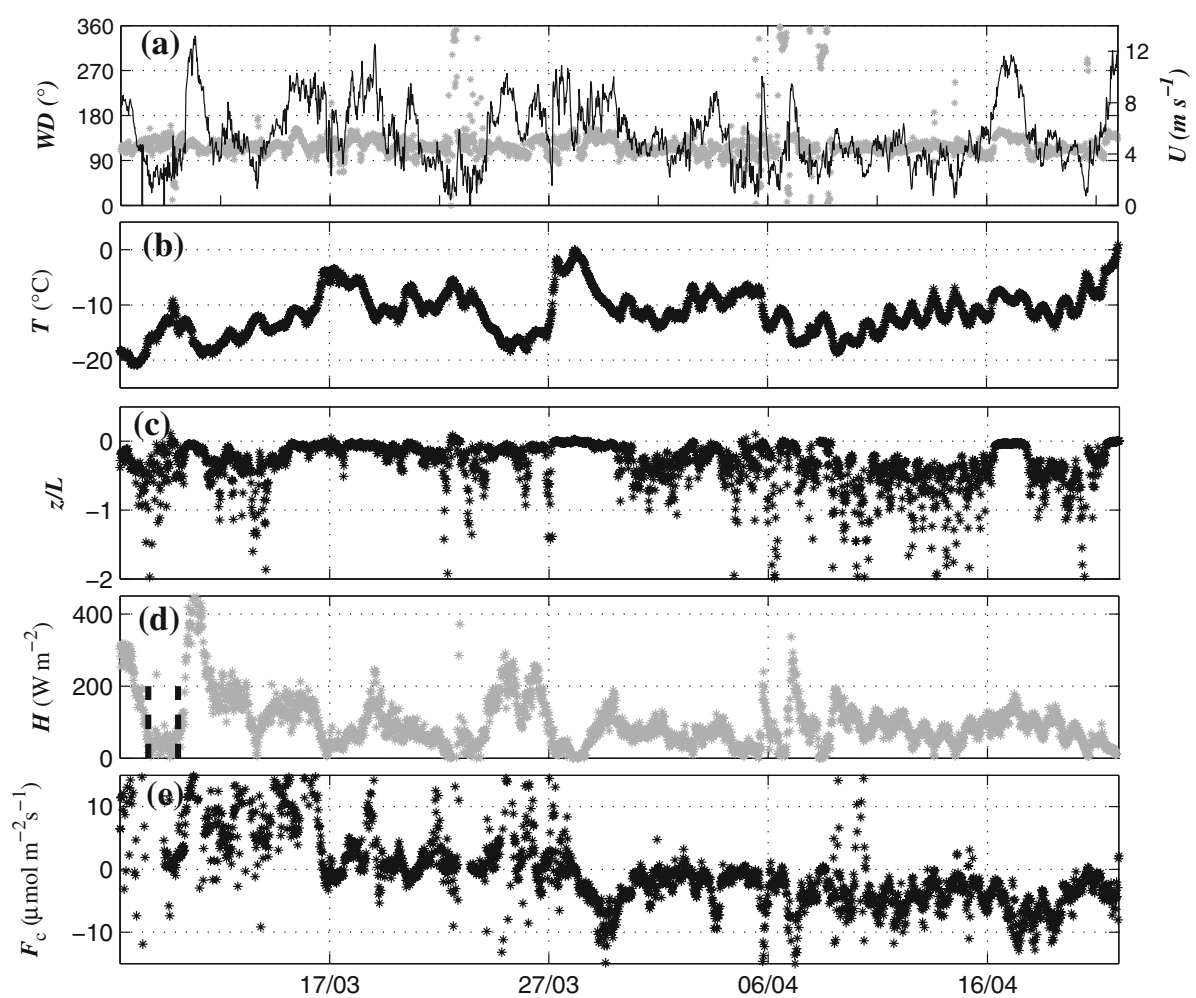

Fig. 2 Observed a wind speed $U$ (thin, black line) and wind direction $W D$ (grey stars), b temperature $T$ at 3-m height above ground, c Monin-Obukhov stability parameter $z / L$, d sensible heat flux $H$, and e $\mathrm{CO}_{2}$ flux $F_{c}$

direction of the air-sea concentration difference of $\mathrm{CO}_{2}$, which is consistent with the fjord acting as a sink of atmospheric $\mathrm{CO}_{2}$. The variability of the flux $F_{c}$ observed during this field campaign reflects the expected development of the concentration of $\mathrm{CO}_{2}$ in the fjord. At the turn of the month from February to March, the biological activity in the water is generally low, and the $\mathrm{CO}_{2}$ concentration in the water often reaches its annual maximum value. Approaching the middle of March, the number of sunlight hours drastically increases, and the net result of photosynthesis and respiration leads to a decreasing partial pressure of $\mathrm{CO}_{2}$ in the water. During the short period from 14 to 19 March, the measured air-sea difference of $\mathrm{pCO}_{2}$ increased from $118 \mu \mathrm{atm}$ to $135 \mu \mathrm{atm}$. From late March, the flux $F_{c}$ was consistently directed downwards.

Figure 3 shows $255 \mathrm{~h}$ of data of the coefficient $C_{H}$ as a function of $z / L$ associated with the wind-direction sector of $090^{\circ}-140^{\circ}$, where each mark (grey) denotes a 30 -min value calculated from Eq. 8, and the black curve is the interpolated function based on the bin averages (black, filled circles). For $z / L<-0.15$, the data scatter around $C_{H}=0.0015$, which is a somewhat larger heat exchange than that normally found over the open ocean, but agrees well with other studies in the same area (Kilpeläinen and Sjöblom 2010), as well as studies over water bodies with limited fetch (e.g., Andreas and Cash 1999). For $z / L>-0.2$, the value of $C_{H}$ increases slightly, and, when the stability becomes closer to neutral for $z / L>-0.1$, the value of $C_{H}$ increases significantly. For $-0.075<z / L<0$ corresponding to $L<-40 \mathrm{~m}$, $C_{H}=0.0018$ on average. 


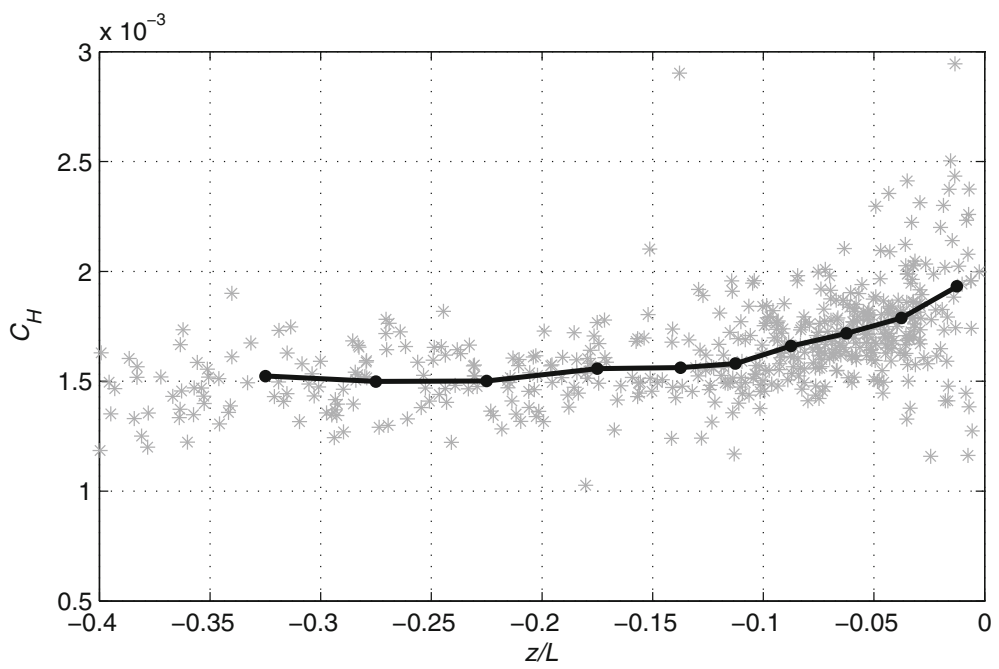

Fig. 3 Bulk exchange coefficient for sensible heat $C_{H}$ as a function of the stability parameter $z / L$ for data from the wind-direction sector $90^{\circ}-140^{\circ}$. The black, solid curve represents the bin averages

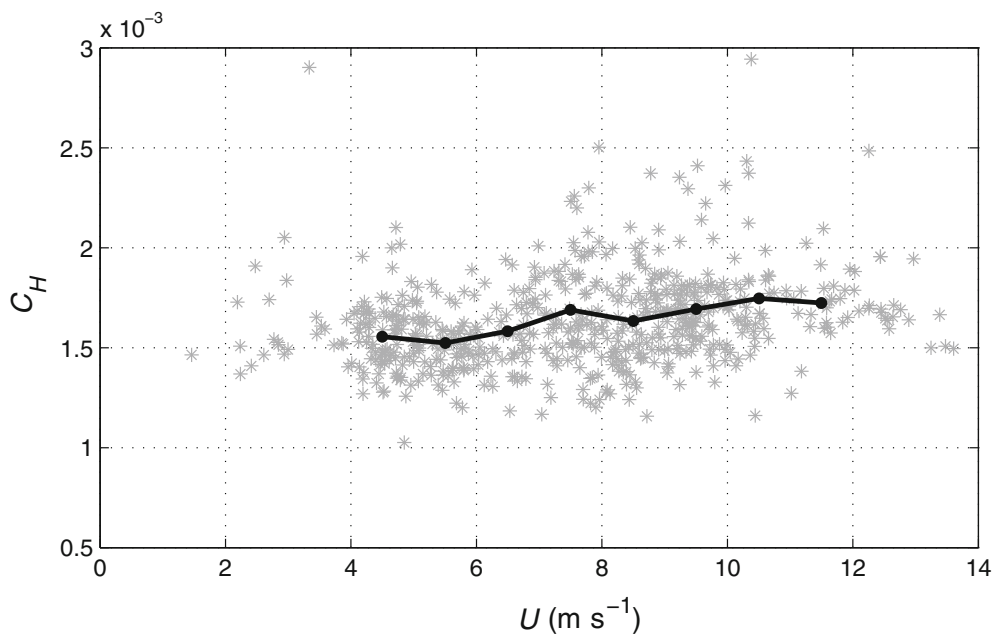

Fig. 4 Bulk exchange coefficient for sensible heat $C_{H}$ as a function of the wind speed at 4-m height $U$ for data from the wind sector $090^{\circ}-140^{\circ}$. The black, solid curve represents the bin averages

With increasing wind speed, the development of the organized structure typical of the CBL is constrained, and a similar dependence as observed in Fig. 3 is also expected when the value of $C_{H}$ is plotted against the wind speed $U$ (Fig. 4). As in Fig. 3, the bin-averaged values of $C_{H}$ are found to increase with increasing values of $U$ in Fig. 4, but with a larger scatter in the $C_{H}$ values. For the data presented in Figs. 3 and 4 , the difference $\theta_{\mathrm{w}}-\theta_{4}$ varies over the broad range of $0.7-19.9^{\circ} \mathrm{C}$, which could explain why a large variation in $\theta_{\mathrm{w}}-\theta_{4}$ values for a specific value of $U$ obscures the expected relation between $C_{H}$ and $U$. Nonetheless, as much as $86 \%$ of the $C_{H}$ data have values $C_{H}>0.0015$ for $U>9 \mathrm{~m} \mathrm{~s}^{-1}$. 


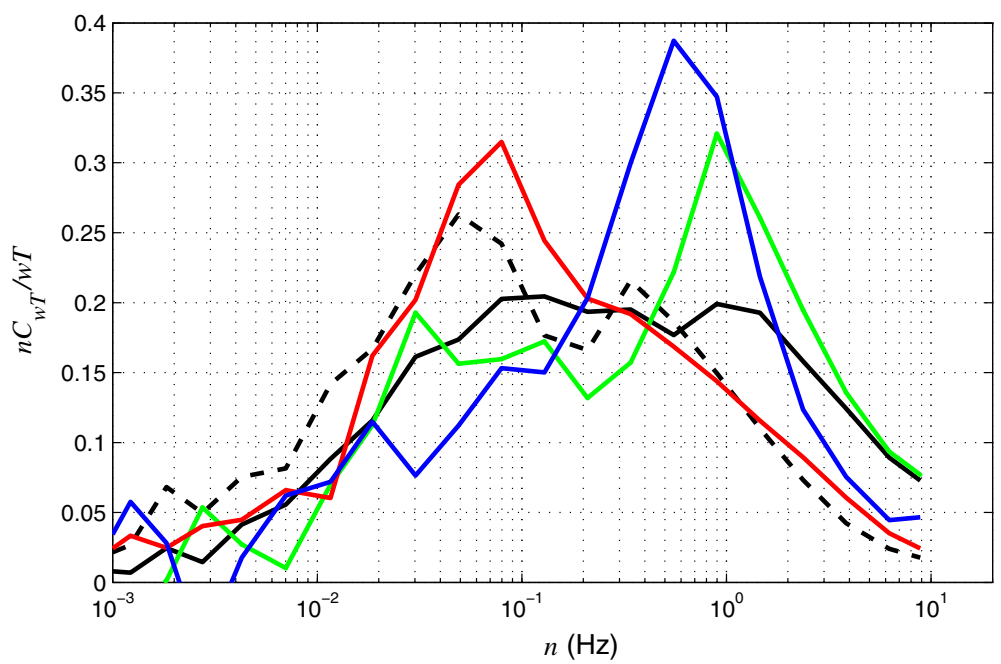

Fig. 5 The normalized mean cospectra of $w T$ shown against the frequency $n$ for $L=-300 \mathrm{~m}$ (green), $L=-$ $100 \mathrm{~m}$ (black solid curve), $L=-20 \mathrm{~m}$ (black dashed curve) and $L=-5 \mathrm{~m}$ (red curve), and stable conditions (blue curve) with $L=600 \mathrm{~m}$

\subsection{Spectral Analysis}

Normalized mean cospectra of $w T$ are shown in Fig. 5 for five different atmospheric stabilities from $L=-5 \mathrm{~m}$ (red curve) to $L=600 \mathrm{~m}$ (blue curve). Here, the mean $w T$ cospectrum is shown in a linear-logarithmic representation, so that the area below the curve is directly proportional to the vertical turbulent flux of temperature. The two black curves are related to the transition regime with $L=-20 \mathrm{~m}$ (black dashed curve) and $L=-100 \mathrm{~m}$ (black solid curve). The green curve is a mean cospectrum for $w T$ during UVCN conditions with $L=$ $-300 \mathrm{~m}$. For the moderately unstable case (red curve), the cospectrum takes an expected shape with one peak at $n=0.08 \mathrm{~Hz}$. As the thermal forcing weakens, this peak decreases in magnitude, and a second peak in the cospectrum of $w T$ develops as the Obukhov length changes from $L=-20 \mathrm{~m}$ to $L=-300 \mathrm{~m}$. For $L=-100 \mathrm{~m}$, the low-frequency peak is reduced and the cospectrum of $w T$ shows a plateau, but for $L=-300 \mathrm{~m}$, the cospectrum of $w T$ is dominated by the high-frequency maxima, which is the signature of the UVCN regime. As a consequence of the large air-sea difference in temperature, high wind-speed events are generally associated with large heat fluxes, so that conditions for $L<-200 \mathrm{~m}$ are rarely observed.

Given the complex terrain surrounding the fjord, we investigate whether this shift in turbulence structure when approaching neutral conditions from the unstable side is connected to the specific upwind topography for the wind-direction sector $090-140^{\circ}$. Normalized mean cospectra of $w T$ are, therefore, shown in Fig. 6 for cases with shorter fetch (upwind distance to land of 1500-2000 m), of height $h_{b}=120 \mathrm{~m}$, and with $L=-100 \mathrm{~m}$ (black solid curve), $L=-20 \mathrm{~m}$ (dashed black curve) and $L=-5 \mathrm{~m}$ (red curve), which represent conditions with mountains located upstream of the fjord of different roughness and boundary-layer height. As the cospectral characteristics of Fig. 6 are qualitatively consistent with the shape of the normalized spectra $n C_{w t}$ in Fig. 5, the topography is not likely to be responsible for the change of the turbulent characteristics when approaching UVCN conditions. As the 


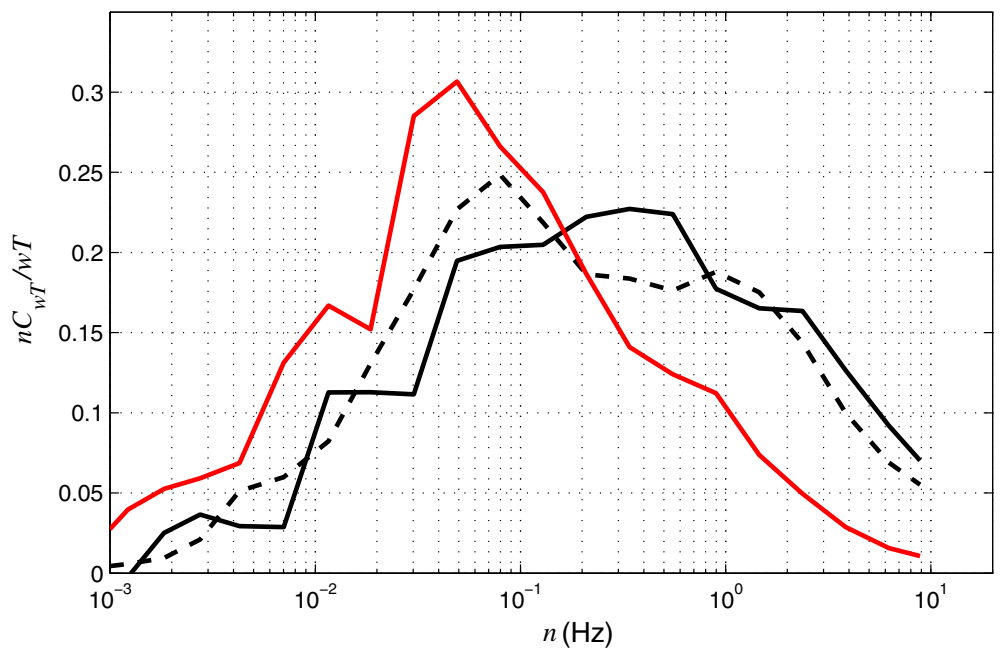

Fig. 6 Normalized mean cospectra of $w T$ for a short fetch and CBL height $h_{b}=120 \mathrm{~m}$ against the frequency $n$ for $L=-100 \mathrm{~m}$ (black solid curve), $L=-20 \mathrm{~m}$ (black dashed curve) and $L=-5 \mathrm{~m}$ (red curve)

atmospheric conditions approach neutrality from the unstable side, a high-frequency peak appears at $L=-20 \mathrm{~m}$, where, similar to the long-fetch case during more unstable conditions (Fig. 5, red curve), the small-scale turbulence is not observed for $L=-5 \mathrm{~m}$ (red curve, Fig. 6). For $L=-100 \mathrm{~m}$ (black solid curve, Fig. 6), the influence from the low-frequency peak almost vanishes, and the normalized cospectrum of $w T$ is dominated by the peak at $f \approx 0.5 \mathrm{~Hz}$.

\subsection{Quadrant Analysis}

Using a quadrant analysis, the contribution to the turbulent flux may be split into four groups (Lu and Willmarth 1973) separated by the individual sign of the two turbulent variables. Here, we use the same definition of the quadrants as Katul et al. (1997) and Sahlée et al. (2008b, 2014), where the two flux components $x$ and $y$ are presented in an $x-y$ plane numbered according to quadrant I ( $x>0$ and $y>0)$, quadrant II $(x<0$ and $y>0)$, quadrant III $(x<0$ and $y<0)$, and quadrant IV $(x>0, y<0)$, with $x=T$ and $y=w$ in Fig. 7, and $x=C$ and $y=w$ in Fig. 8. Quadrants I and III (II and IV) give a positive (negative) contribution to the upwards heat flux. The hyperbolic hole of size $H$ introduced by Willmarth and Lu (1974) and defined as

$$
H=\left|x^{\prime} y^{\prime}\right| /\left|\overline{x^{\prime} y^{\prime}}\right|,
$$

illustrates the relative importance of different eddies for the total flux. Here, the point $\left(x^{\prime}, y^{\prime}\right)$ lies on a hyperbolic function bounding the whole region in the $x-y$ plane for each quadrant. By varying the value of $H$ from zero to 10, the flux fraction from the different quadrants can be studied for flux events of magnitude one to 10 times that of the average flux. Using the method from Raupach (1981), the flux fraction $S_{i H}$ is determined from

$$
S_{i H}=\left[x^{\prime} y^{\prime}\right]_{i H} / \overline{x^{\prime} y^{\prime}},
$$




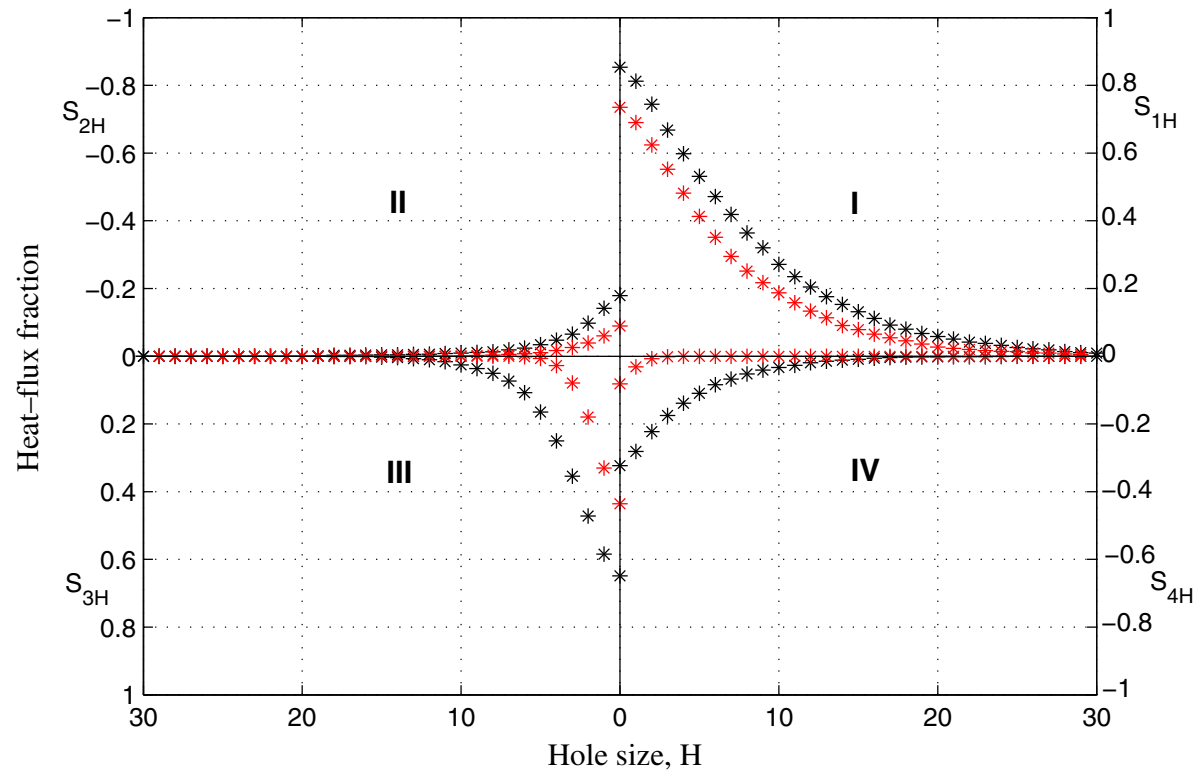

Fig. 7 The flux fraction ( $y$-axis) for the corresponding hole size ( $x$-axis) obtained from a quadrant analysis of the heat flux for a moderately unstable case with $L=-5 \mathrm{~m}$ (red) and a UVCN situation with $L=-300 \mathrm{~m}$ (black). Quadrants I and III give positive contributions to the vertical heat flux

where subscript $i$ refers to the quadrant number, and the brackets indicate a conditional average, which is formally defined from the conditioning function $I_{i H}$ defined as $I_{i H}=1$ within the $i$ th quadrant, and $\left|x^{\prime} y^{\prime}\right| \geq H\left|\overline{x^{\prime} y^{\prime}}\right|=0$ otherwise, giving

$$
\left[x^{\prime} y^{\prime}\right]_{i H}=\lim _{T \rightarrow \infty} \frac{1}{T} \int_{0}^{T} x^{\prime} y^{\prime}(t) I_{i H}(t) d t
$$

The quadrant flux fractions are normalized quantities, such that

$$
\sum_{i=1}^{4} S_{i, 0}=1 .
$$

Figure 7 shows a quadrant plot for a moderately unstable case with $L=-5 \mathrm{~m}$ (red) and a UVCN situation with $L=-300 \mathrm{~m}$ (black), which is also shown in Fig. 5 (green). For the moderately unstable case, the majority of the flux is constrained to quadrant $\mathrm{I}$, implying that the flux originates from an upwards transfer of warm air. The case related to $L=-300 \mathrm{~m}$ displays a different behaviour, with a large part of the positive contribution to the heat flux originating from quadrant III, corresponding to a downwards transfer of cold air from above. A closer inspection of the case related to $L=-300 \mathrm{~m}$ shows that for $H=4$, the sum of the flux fraction is 0.66 and $S_{3,4}=0.25$, meaning that $66 \%$ of the flux occurs in events where the flux is more than four times the average value, and where the flux fraction from quadrant III is $25 \%$. For the more unstable case related to $L=-5 \mathrm{~m}$ with $H=4$, the sum of the flux fractions is 0.49 , and the flux fraction from quadrant III is below $3 \%$. 


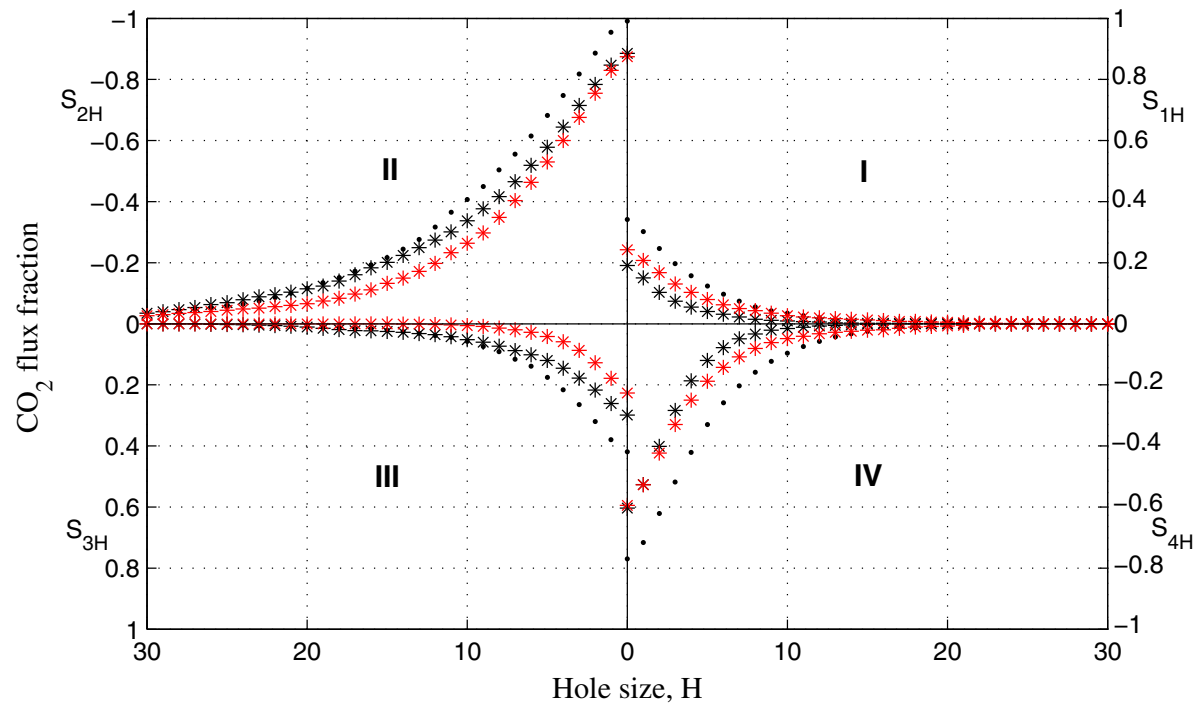

Fig. 8 The flux fraction ( $y$-axis) for the corresponding hole size ( $x$-axis) based on a quadrant analysis of the mean $\mathrm{CO}_{2}$ flux for a moderately unstable case with $L \approx-6 \mathrm{~m}$ (red) based on two 30-min periods, the start of transition with $L \approx-30 \mathrm{~m}$ (black stars) based on two 30-min periods, and a case with $L=-150 \mathrm{~m}$ (black dots) based on two 30-min periods. Quadrants II and IV contribute to the measured downwards $\mathrm{CO}_{2}$ flux, where quadrant II corresponds to updrafts of air with lower concentrations of $\mathrm{CO}_{2}$, and quadrant IV to downdrafts of air with higher concentrations of $\mathrm{CO}_{2}$

\subsection{Implications for the Air-Sea Gas Transfer of $\mathrm{CO}_{2}$}

Section 4.2 shows that the vertical turbulent flux of temperature is enhanced as conditions become neutral from the unstable side. As mentioned earlier, the enhanced fluxes of temperature and humidity during UVCN conditions reported in Smedman et al. (2007a, b) and Sahlée et al. (2008a, b) are the result of the different properties (colder and drier) of the air aloft, which is transported downwards by detached eddies. The quadrant analysis of the heat flux presented in Fig. 7 also shows an enhanced contribution from downdrafts of cold air for the UVCN regime, which possibly enhance the magnitude of the flux $w T$, and cause the increase in the value of $C_{H}$ for this regime. For $\mathrm{CO}_{2}$, while we do not expect as large differences in concentration between the upper and lower part of the atmospheric surface layer as for temperature, it is possible that the imprints of the additional small-scale turbulence increase the magnitude of the water-side turbulence, and thereby the transfer velocity of the air-sea transfer of $\mathrm{CO}_{2}$. In Fig. 8, a quadrant analysis is presented for three cases with $L$ $\approx-6 \mathrm{~m}$ (red dot), $L \approx-30 \mathrm{~m}$ (black stars) and $L=-150 \mathrm{~m}$ (black dots), with the positive contributions to the measured downwards flux $F_{c}$ from quadrants II and IV. Similar to the quadrant analysis of the cospectrum $w T$ (Fig. 7), the increasing significance of downdrafts when approaching the UVCN regime are also observed for the flux $F_{c}$ (here quadrant IV) when $L=-150 \mathrm{~m}$.

In Fig. 9, the normalized mean cospectra of $w C$ for the cases $L=-150 \mathrm{~m}$ (green), $L=-$ $100 \mathrm{~m}$ (black solid), $L=-50 \mathrm{~m}$ (black dashed) and $L=-5 \mathrm{~m}$ (red) are shown, and present a behaviour qualitatively similar to the $w T$ cospectra (Fig. 5). For $L=-5 \mathrm{~m}$, the cospectrum of $w C$ shows a maximum at $0.03 \mathrm{~Hz}$, but a second peak near $1 \mathrm{~Hz}$ is present in the highfrequency part of the cospectrum for $L=-50 \mathrm{~m}$, which grows in magnitude as conditions 


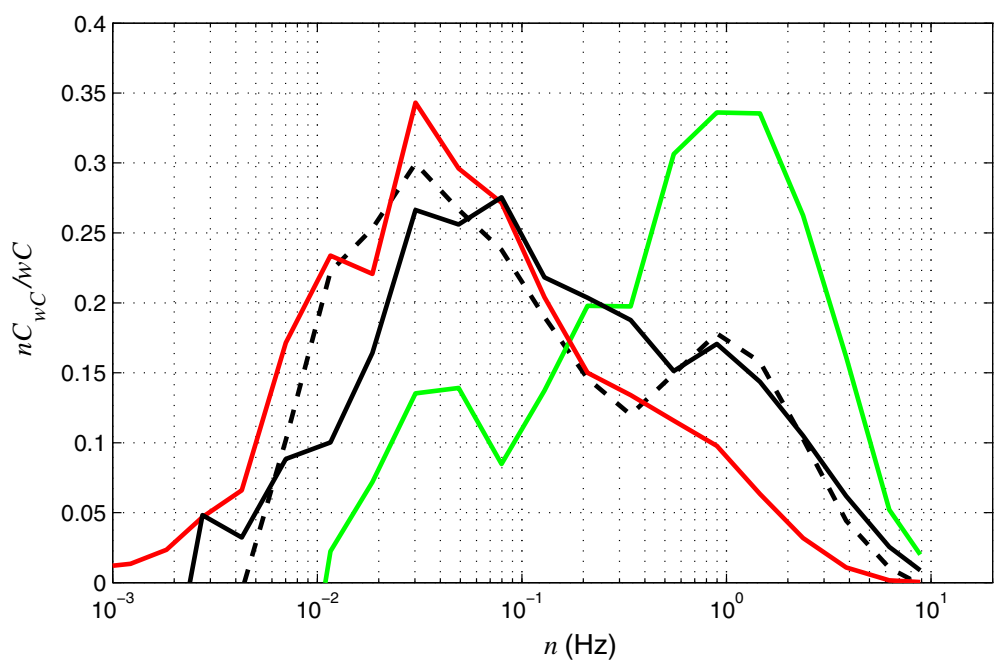

Fig. 9 Normalized mean cospectra of $w C$ against the frequency $n$ for data from sector $\mathrm{S}_{2}$ for the cases $L=-$ $150 \mathrm{~m}$ (green), $L=-100 \mathrm{~m}$ (black solid curve), $L=-50 \mathrm{~m}$ (black dashed curve) and $L=-5 \mathrm{~m}$ (red curve). Each mean cospectrum is based on $2-7 \mathrm{~h}$ of consecutive measurements

become closer to neutral, with the cospectrum for $L=-100 \mathrm{~m}$ displaying a plateau shape. For $L=-150$ m representing the UVCN regime (the same case as in Fig. 8), the low-frequency peak has almost vanished, and instead the maximum at $1 \mathrm{~Hz}$ is very distinct.

To qualitatively investigate the impact of the small-scale turbulence on the air-sea gas flux, the gas-transfer velocity is preferably studied, because the influence from other processes affecting the transfer efficiency can be effectively removed. The two major processes controlling the gas-transfer velocity over the fjord during these two months of measurements include the wind stress and water-side convection (Andersson et al. 2017). After removal of the latter using Eq. 7, and the former using Eq. 5, the impact from the small-scale turbulence arising during UVCN conditions on the value of $k_{660}$ is revealed (Fig. 10). Here, data are separated by wind speed, with $U>6.5 \mathrm{~m} \mathrm{~s}^{-1}$ denoted by red dots, and $U<6.5 \mathrm{~m} \mathrm{~s}^{-1}$ by grey dots. During more unstable conditions, the gas-transfer velocities are well described by the sum of $k_{w s c}$ and $k_{W 09}$, so that the mean value of $k_{660}-\left(k_{w s c}+k_{W 09}\right)$ scatters around zero. For data closer to neutral conditions corresponding to $-0.2<z / L<-0.1$, the mean value of $k_{660}-\left(k_{w s c}+k_{W 09}\right)$ increases with $z / L$, but a larger scatter can be observed, where the case $L$ $\approx-30 \mathrm{~m}$ has similar flux characteristics as the moderately unstable data (black stars, Fig. 8), and is associated with a low value of $k_{660}-\left(k_{w s c}+k_{W 09}\right)$ (black circle, Fig. 10).

As conditions became more neutral and $z / L>-0.1$ (see the black dashed line in Fig. 10), a different behaviour is also observed for the gas-transfer velocities of $\mathrm{CO}_{2}$; the scatter decreases and as much as $80 \%$ of the data attain values $k_{660}-\left(k_{w s c}+k_{W 09}\right)>10 \mathrm{~cm} \mathrm{~h}^{-1}$. The data within this regime are characterized by larger values of $u *$, resulting in enhanced water-side turbulence, and an enhanced contribution of the $\mathrm{CO}_{2}$ flux from downdrafts of air with higher concentrations of $\mathrm{CO}_{2}$, such as the case $L=-150 \mathrm{~m}$ (green circle), which is also presented in Fig. 8 (black dots) and Fig. 9 (green curve). 


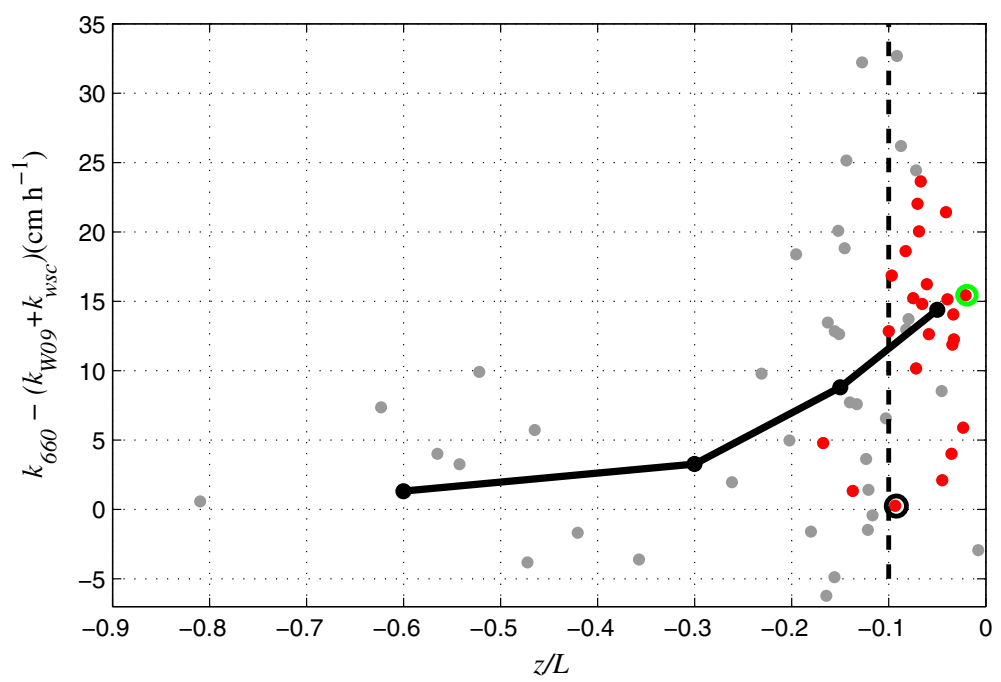

Fig. 10 The value of $k_{660}-\left(k_{W 09}+k_{w s c}\right)$ as a function of the stability parameter $z / L$. Red markers denote data for $U>6.5 \mathrm{~m} \mathrm{~s}^{-1}$. The black curve shows the bin-averaged values of $k_{660}-\left(k_{W 09}+k_{w s c}\right)$ for each stability class. Open circles represent the same data presented in Fig. 8, with the black circle indicating $L \approx-30 \mathrm{~m}$, and the green circle $L=-150 \mathrm{~m}$

\section{Summary and Conclusions}

In winter, a CBL develops over the high Arctic fjord where the height of the boundary layer increases with increasing distance from land. The combination of a large air-sea temperature gradient and relatively high wind speed results in a well-mixed boundary layer with stability $-1<z / L<-0.03$. During conditions with stability $-0.2<z / L<0$, measurements show enhanced vertical fluxes of heat not associated with the local gradient. From being relatively constant for $z / L<-0.15$, the bulk transfer coefficient increases from a typical mean value of $C_{H}=0.0015$ to $C_{H}=0.0018$ for $z / L=-0.075$. The increase of the bulk transfer as a function of wind speed is not as prominent, which is probably a result of the large variation in temperature gradient. The cospectra of $w T$ show that the enhanced heat transfer is associated with small-scale turbulence with a peak at around $f=1 \mathrm{~Hz}$, which gradually grows in magnitude as conditions became more neutral, and the relative contribution from the low-frequency peak at $f=0.003 \mathrm{~Hz}$ decreases in magnitude. For $L=-300 \mathrm{~m}$, the high-frequency maximum dominates the normalized cospectrum of $w T$. Simultaneously, the contribution from downdrafts to the total heat flux increases from $3 \%$ for $L=-5 \mathrm{~m}$ to $25 \%$ of the flux for $L=$ $-300 \mathrm{~m}$. This is the signature of the UVCN regime presented in a series of papers.

Small-scale turbulence, which is potentially caused by detached eddies, also affects the air-sea exchange of $\mathrm{CO}_{2}$. A quadrant analysis of the $\mathrm{CO}_{2}$ flux shows that, as conditions approach neutral and the Obukhov length decreases from $L=-30 \mathrm{~m}$ to $L=-150 \mathrm{~m}$, the contribution to the $\mathrm{CO}_{2}$ flux from downdrafts of air with higher concentrations of $\mathrm{CO}_{2}$ increases. Similar to the flux $w T$, the increased contribution from downdrafts to the air-sea $\mathrm{CO}_{2}$ flux is found to coincide with the formation and increase in a high-frequency peak in the cospectra for $w C$. After removing the effect from the two dominant processes affecting the gas-transfer velocity using published parametrizations of water-side convection $\left(k_{w s c}\right)$ and shear-induced turbulence from the mean wind speed $\left(k_{W 09}\right)$, the gas-transfer velocity was 
examined, showing the values of $k_{660}-\left(k_{W 09}+k_{w s c}\right)$ scattered around zero for moderately unstable conditions. However, when approaching the UVCN regime $(z / L>-0.1$ and $U$ $\left.>6.5 \mathrm{~m} \mathrm{~s}^{-1}\right)$, the values of $k_{660}-\left(k_{W 09}+k_{w s c}\right)$ are found to increase, where as much as $80 \%$ of the data take values $k_{660}-\left(k_{W 09}+k_{w s c}\right)>0.1 \mathrm{~m} \mathrm{~h}^{-1}$. These results are somewhat surprising since one does not expect the vertical gradient of $\mathrm{CO}_{2}$ in the atmosphere to be as large as the vertical gradient for temperature. We speculate that a part of the enhanced $\mathrm{CO}_{2}$ flux is due to imprints on the water surface by the additional small-scale turbulence resulting in increased levels of water-side turbulence.

In summary, we show the possible importance of the UVCN regime for the air-sea exchange of heat in the Arctic during winter, and that the UVCN regime affects the air-sea exchange of $\mathrm{CO}_{2}$, becoming significant for stabilities $z / L \geq-0.1$. During the nearly 2 months of continuous measurements, as much as $30 \%$ of the data were associated with conditions $-0.1 \leq z / L<0$. We believe that a larger dataset of gas-transfer velocities would emphasize the relevance of the UVCN regime for air-sea gas exchange.

Acknowledgements The authors wish to thank Tor de Lange at the Geophysical Institute, University of Bergen, Norway for his useful support and technical assistance during the fieldwork. Data supporting the results will be provided upon request.

Open Access This article is distributed under the terms of the Creative Commons Attribution 4.0 International License (http://creativecommons.org/licenses/by/4.0/), which permits unrestricted use, distribution, and reproduction in any medium, provided you give appropriate credit to the original author(s) and the source, provide a link to the Creative Commons license, and indicate if changes were made.

\section{References}

Anderson DE, Verma SB (1985) Turbulence spectra of $\mathrm{CO}_{2}$, water vapour temperature and wind velocity fluctuations over a crop surface. Boundary-Layer Meteorol 33:1-14

Andersson A, Rutgersson A, Sahlée E (2014) Using a high-frequency fluorescent oxygen probe in atmospheric eddy covariance applications. J Atmos Ocean Technol 31:2498-2511. https://doi.org/10.1175/JTECHD-13-00249.1

Andersson A, Falck E, Sjöblom A, Kljun N, Sahlée E, Omar AM, Rutgersson A (2017) Air-sea gas transfer in high Arctic fjords. J Geophys Lett. https://doi.org/10.1002/2016g1072373

Andreas EL, Cash BA (1999) Convective heat transfer over wintertime leads and polynyas. J Geophys Res Oceans 104(C11):25721-25734

Andreas EL, Murphy B (1986) Bulk transfer coefficients for heat and momentum over leads and polynyas. J Phys Oceanogr 16:1875-1883

Asher WE, Wanninkhof R (1998) The effect of bubble-mediated gas transfer on purposeful dual-gaseous tracer experiments. J Geophys Res 103:10555-10560

Bell TG, Landwehr S, Miller SD, de Bruyn WJ, Callaghan AH, Scanlon B, Ward B, Yang M, Saltzman ES (2017) Estimation of bubble-mediated air-sea gas exchange from concurrent DMS and $\mathrm{CO}_{2}$ transfer velocities at intermediate-high wind speeds. Atmos Chem Phys 17:9019-9033. https://doi.org/10.5194/ acp-17-9019-2017

Drushka K, Asher WE, Ward B, Walesby K (2016) Understanding the formation and evolution of rainformed fresh lenses at the ocean surface. J Geophys Res Oceans 121:2673-2689. https://doi.org/10. 1002/2015JC011527

Else BGT, Papakyriakou TN, Galley RJ, Drennan WM, Miller LA, Thomas H (2011) Wintertime $\mathrm{CO}_{2}$ fluxes in an Arctic polynya using eddy covariance: Evidence for enhanced air-sea gas transfer during ice formation. J Geophys Res Oceans 116(C9)

Garratt JR (1992) The atmospheric boundary layer. Cambridge University Press, Cambridge

Ho DT, Bliven LF, Wanninkhof R, Schlosser P (1997) The effect of rain on air-water gas exchange. Tellus B 49:149-158

Ho DT, Zappa CJ, McGillis WR, Bliven LF, Ward B, Dacey JWH, Schlosser P, Hendriks MB (2004) Influence of rain on air-sea gas exchange: lessons from a model ocean. J Geophys Res 109:C08S18 
Högström U (1996) Review of some basic characteristic of the atmospheric surface layer. Boundary-Layer Meteorol 78:215-246

Högström U, Hunt JCR, Smedman A (2002) Theory and measurements for turbulence spectra and variances in the atmospheric neutral surface layer. Boundary-Layer Meteorol 103(1):101-124

Hunt JCR, Carlotti P (2001) Statistical structure at the wall of the high Reynolds number turbulent boundary layer. Flow Turbul Combust 66:453-475

Hunt JC, Morrison JF (2000) Eddy structure in turbulent boundary layers. Eur J Mech B/Fluids 19(5):673-694

Jeffery C, Woolf D, Robinson I, Donolon C (2007) One-dimensional modelling of convective $\mathrm{CO}_{2}$ exchange in the tropical Atlantic. Ocean Modell 19(3-4):161-182

Kaimal JC, Wyngaard JC, Izumi Y, Coté OR (1972) Spectral characteristics of surface layer turbulence. Q J Roy Meteorol Soc 98:563-589

Katul G, Kuhn G, Schieldge J, Hsieh C-I (1997) The ejection-sweep character of scalar fluxes in the unstable surface layer. Boundary-Layer Meteorol 83:1-26

Kilpeläinen T, Sjöblom A (2010) Momentum and sensible heat exchange in an ice-free Arctic fjord. BoundaryLayer Meteorol 134(1):109-130

Le Quéré C, Moriarty R, Andrew RM, Peters GP, Ciais P, Friedlingstein P, Jones SD, Sitch S, Tans P, Arneth A, Boden TA, Bopp L, Bozec Y, Canadell JG, Chini LP, Chevallier F, Cosca CE, Harris I, Hoppema M, Houghton RA, House JI, Jain AK, Johannessen T, Kato E, Keeling RF, Kitidis V, Klein-Goldewijk K, Koven C, Landa CS, Landschützer P, Lenton A, Lima ID, Marland G, Mathis JT, Metzl N, Nojiri Y, Olsen A, Ono T, Peng S, Peters W, Pfeil B, Poulter B, Raupach MR, Regnier P, Rödenbeck C, Saito S, Salisbury JE, Schuster U, Schwinger J, Séférian R, Segschneider J, Steinhoff T, Stocker BD, Sutton AJ, Takahashi T, Tilbrook B, van der Werf GR, Viovy N, Wang Y-P, Wanninkhof R, Wiltshire A, Zeng N (2015) Global carbon budget 2014. Earth Syst Sci Data 7(1):47-85. https://doi.org/10.5194/essd-7-472015

Liss PS, Merlivat L (1986) Air-sea gas exchange rates: introduction and synthesis. In: Buat-Menard P (ed) The Role of Air-Sea Exchange in Geochemical Cycling. Reidel, Dordrecht, pp 113-127

Lu SS, Willmarth WW (1973) Measurements of the structure of the Reynolds stress in a turbulent boundary layer. J Fluid Mech 60:481-511

MacIntyre S, Eugster W, Kling GW (2002) The critical importance of buoyancy flux for gas flux across the air-water interface, in: Donelan MA, Drennan WM, Saltzman ES, Wanninkhof R (eds) Gas Transfer at Water Surfaces, Geophysical Monograph, American Geophysical Union, Washington DC, vol 127, pp $13-28$

Mason PJ, Sykes RI (1982) A two-dimensional numerical study of horizontal roll vortices in an inversion capped planetary boundary layer. Q J R Meteorol Soc 108:801-823

Norman M, Rutgersson A, Sörensen LL, Sahlée E (2012) Methods for estimating air-sea fluxes of $\mathrm{CO}_{2}$ using high frequency measurements. Boundary-Layer Meteorol 144:379-400. https://doi.org/10.1007/s10546012-9730-9

Ohtaki E, Matsui T (1982) Infrared device for simultaneous measurement of fluctuations of atmospheric carbon dioxide and water vapor. Boundary-Layer Meteorol 24:109-119

Othaki E (1982) Kolmogorov constant for carbon dioxide in the atmospheric surface layer over a paddy field. Boundary-Layer Meteorol 23(2):153-159

Raupach MR (1981) Conditional statistics of Reynolds stress in roughwall and smooth-wall turbulent boundary layers. J Fluid Mech 108:363-382

Rutgersson A, Smedman A (2010) Enhanced air-sea $\mathrm{CO}_{2}$ transfer due to water-side convection. J Mar Syst 80(1):125-134

Rutgersson A, Smedman A, Sahlée E (2011) Oceanic convective mixing and the impact on air-sea gas transfer velocity. Geophys Res Lett 38(2):L02602. https://doi.org/10.1029/2010GL045581

Sahlée E, Smedman A, Högström U, Rutgersson A (2008a) Reevaluation of the bulk exchange coefficient for humidity at sea during unstable and neutral conditions. J Phys Oceangr 38(1):257-272

Sahlée E, Smedman A, Högström U, Rutgersson A (2008b) Spectra of CO2 and water wapour in the marine atmospheric surface layer. Boundary-Layer Meteorol 126(2):279-295

Sahlée E, Smedman A, Rutgersson A, Högström U (2008c) Influence of a new turbulence regime on the global air-sea heat fluxes. J Clim 21(22):5925-5941

Sahlée E, Rutgersson A, Podgrajsek E, Bergström H (2014) Influence from surrounding land on the turbulence measurements above a lake. Boundary-Layer Meteorol 150(2):235-258

Sjöblom A, Smedman A (2004) Comparison between eddy-correlation and inertial dissipation methods in the marine atmospheric surface layer. Boundary-layer Meteorol 110(2):141-164

Smedman A, Högström U, Hunt JCR, Sahlée E (2007a) Heat/mass transfer in the slightly unstable atmospheric surface layer. Q J R Meteorol Soc 133:37-51 
Smedman A, Högström U, Sahlée E, Johansson C (2007b) Critical reevaluation of the bulk transfer coefficient for sensible and latent heat over the ocean during unstable and neutral conditions. Q J R Meteorol Soc $1: 227-250$

Tetzlaff A, Lüpkes C, Hartmann J (2015) Aircraft-based observations of atmospheric boundary-layer modification over Arctic leads. Q J R Meteorol Soc 141:2839-2856. https://doi.org/10.1002/qj.2568

Verma S, Anderson D (1984) Kolmogorov constants for $\mathrm{CO}_{2}$, wind velocity, air temperature, and humidity fluctuations over a crop surface. Boundary-Layer Meteorol 28:161-167. https://doi.org/10.1007/ BF00119461

Vickers D, Mahrt L (1997) Quality control and flux sampling problems for tower and aircraft data. J Atmos Ocean Technol 14:512-526

Wanninkhof R (1992) Relationship between wind speed and gas exchange over the ocean. J Geophys Res 97:7373-7382

Wanninkhof R, Asher WE, Ho DT, Sweeney C, McGillis WR (2009) Advances in quantifying air-sea gas exchange and environmental forcing. Annu Rev Mar Sci 1:213-244

Webb EK, Pearman GI, Leuning R (1980) Correction of flux measurements for density effects due to heat water vapor transport. Q J R Meteorol Soc 106:85-100

Willmarth WW, Lu SS (1974) Structure of the Reynolds stress and the occurrence of bursts in the turbulent boundary layer. Adv Geophys 18A:287-314

Woolf DK (1993) Bubbles and the air-sea transfer velocity of gases. Atmos-Ocean 31(4):517-540

Woolf DK (1997) Bubbles and their role in air-sea gas exchange. In: Liss P, Duce R (eds) The Sea Surface and Global Change. Cambridge University Press, New York, pp 173-205

Zappa C, Ho D, McGillis WR, Banner M, Dacey J, Bliven L, Ma B, Nystuen J (2009) Rain-induced turbulence and air-sea gas transfer. J Geophys Res 114:C07009. https://doi.org/10.1029/2008JC005008

Publisher's Note Springer Nature remains neutral with regard to jurisdictional claims in published maps and institutional affiliations.

\section{Affiliations}

\section{A. Andersson ${ }^{1,2}$ (D) A. Sjöblom ${ }^{1,3} \cdot$ E. Sahlée ${ }^{1} \cdot$ E. Falck $^{3} \cdot$ A. Rutgersson ${ }^{1}$}

1 Department of Earth Sciences, Uppsala University, Uppsala, Sweden

2 Department of Ecotechnology and Sustainable Building Engineering, Mid-Sweden University, Östersund, Sweden

3 Department of Arctic Geophysics, University Centre in Svalbard, Longyearbyen, Norway 